\title{
Natural Health Product-Drug Interaction Causality Assessment in Pediatric Adverse Event Reports Associated with Attention-Deficit/Hyperactivity Disorder Medication
}

\author{
Hajra Mazhar, BSc, ${ }^{1,2}$ Brian C. Foster, PhD, ${ }^{3}$ Candace Necyk, MSc, ${ }^{4}$ Paula M. Gardiner, MD, ${ }^{5}$ \\ Cory S. Harris, $\mathrm{PhD},{ }^{2,6}$ and Philippe Robaey, $\mathrm{MD}, \mathrm{PhD}^{1,7}$
}

\begin{abstract}
Background: Some pediatric patients with attention-deficit/hyperactivity disorder (ADHD) use natural health products (NHPs) such as herbal remedies. Although herbal remedies are generally considered to be safe when they are used appropriately, they may contain active components that can interact with medications being used concurrently, with potential for NHP-drug interactions leading to adverse events.

Objectives: The objectives of this study were (1) to identify adverse event reports (AERs) involving commonly used herbal remedies and ADHD prescription medicines in children and adolescents; (2) to evaluate the quality of collected AERs; and (3) to assess whether NHP-drug interactions can be causally linked to reported adverse events.

Methods: We systematically searched the FDAble database (FDAble.com) for herbal remedies commonly used by patients (4-18 years old) also taking ADHD drugs from 1997 to 2015. We assessed the completeness of the AERs and used three causality assessment tools modified for NHPs (Naranjo Adverse Drug Reaction Probability Scale, HORN Drug Interaction Probability Scale, and World Health Organization Uppsala Monitoring Centre Scale).

Results: Of the 23 identified AERs involving both an herbal remedy and an ADHD prescription medication, most involved multiple ( $>3$ ) substances with inadequate detail to assess multiple potential interactions. Following data extraction and evaluation of completeness, five AERs involving only one herbal remedy and one ADHD medication were evaluated for causality. An NHP-drug interaction was assessed to be probable in one case and to be possible in another. Both these reports involved a methylphenidate formulation and St. John's wort.

Conclusions: Eighteen of the 23 identified AERs involving both an herbal remedy and an ADHD drug also involved other multiple ingredient products. The reporting quality was poor for the five AERs examined. Further research is needed to study the interaction between St. John's wort and methylphenidate.
\end{abstract}

Keywords: herb-drug interaction, dietary supplements, botanicals, integrative medicine, pharmacovigilance, doctor-patient communication

\section{Introduction}

$\mathbf{C}$ OMPLEMENTARY AND INTEGRATIVE MEDICINE (CIM) encompasses a group of health care and medical systems, practices, and products that are not typically taught in conventional medicine training and includes natural health products (NHPs), mind-body practices (e.g., yoga, chiropractic and osteopathic manipulation, meditation), and other complementary health approaches (e.g., traditional healers, Ayurveda, Traditional Chinese Medicine, homeopathy, naturopathy) (National Center for Complementary and Integrative Health 2018). NHPs, also known as dietary supplements in the United States, represent the most widely used form of CIM and include vitamins, minerals, herbal remedies, probiotics, amino acids, and essential fatty acids. In the United States, they are

${ }^{1}$ Children's Hospital of Eastern Ontario Research Institute, Ottawa, Canada.

${ }^{2}$ Department of Biology, Faculty of Science, University of Ottawa, Ottawa, Canada.

${ }^{3}$ Department of Cellular and Molecular Medicine, Faculty of Medicine, University of Ottawa, Ottawa, Canada.

${ }^{4}$ Faculty of Pharmacy and Pharmaceutical Sciences, University of Alberta, Edmonton, Canada.

${ }^{5}$ Department of Family Medicine, University of Massachusetts Medical School, Worcester, Massachusetts.

${ }^{6}$ School of Epidemiology and Public Health, University of Ottawa, Ottawa, Canada.

${ }^{7}$ CHU Sainte-Justine Research Centre, Université de Montreal, Montreal, Canada.

Funding: This study was supported by the University of Ottawa. 
regulated by the U.S. Food and Drug Administration (FDA) (2018). In Canada, NHPs include vitamins and minerals, herbal remedies, homeopathic remedies, traditional medicine, probiotics, and other products such as amino acids and essential fatty acids and are regulated by the Natural and Non-prescription Health Products Directorate (NNHPD) of the federal government (Health Canada 2015).

In 2016, Canadians and Americans spent $\$ 8.8$ billion and $\$ 28.3$ billion, respectively, on CIM therapies out-of-pocket (National Center for Complementary and Integrative Health 2016; Esmail 2017). For children, an estimated $\$ 1.9$ billion was spent in 2016 by Americans (National Center for Complementary and Integrative Health 2016). This represents a large portion of out-of-pocket spending as the use of CIM becomes more mainstream. According to the 2010 Ipsos Reid survey, 73\% of Canadians had used NHPs and $32 \%$ used them on a daily basis (Ipsos 2011). In the United States, $75 \%$ of adults had used dietary supplements (The Council for Responsible Nutrition 2018).

Surveys investigating CIM use in North American pediatric populations suggest that up to $40 \%$ of healthy children (Spigelblatt et al. 1994; Ottolini et al. 2001; Loman 2003; Jean and Cyr 2007; Barnes et al. 2008) and up to $75 \%$ of children with chronic illness use some form of CIM (Neuhouser et al. 2001; Ball et al. 2005; Post-White et al. 2009). The use of CIM in general tends to be higher in children with mental health conditions, and among these children, those with attention-deficit/hyperactivity disorder (ADHD) are the most common users of CIM (Birdee et al. 2010; Adams et al. 2013; Huang et al. 2013; Kemper et al. 2013; Wang et al. 2018). CIM use for ADHD tends to be higher due to the chronic nature of the condition, occurrence with comorbid conditions, parental concerns about adverse events from conventional drugs, and desire for a natural or holistic approach (Stubberfield et al. 1999; Chan et al. 2003; Sinha and Efron 2005; Huang et al. 2013; Kemper et al. 2013; Wang et al. 2018).

Among the various modalities of CIM, herbal remedies are one of the most commonly used NHPs by pediatric neurology patients and ADHD patients (Chan et al. 2003; Sinha and Efron 2005; Wang et al. 2018). Although there is lack of research on the concurrent use of NHPs with conventional psychostimulants prescribed, herbal remedies have previously been reported to be used commonly alongside psychostimulants (Hazell et al. 1996; Galicia-Connolly et al. 2014). Herbal remedies or botanicals are derived from plant materials or preparations from one or more plants and have gained particular attention due to their complex nature (World Health Organization 2005a, 2015). While herbal remedies are generally safe when used properly, they are not risk free (Health Canada 2015) and can pose a risk of interactions with pharmaceutical drugs, potentially rendering these treatments ineffective or toxic, resulting in adverse events (Birdee et al. 2010; Noras et al. 2013; World Health Organization 2015). Herbal remedies, either as single entity or as mixed formulations, can contain raw or processed medicinal and nonmedicinal ingredients, which may be bioactive or nonactive substances. They can act synergistically, antagonistically, or additively to each other and to other substances being used concurrently, with potential for interactions. This may affect efficacy and/or result in adverse events (Cheng et al. 2010; Benzie and Wachtel-Galor 2011).

According to the International Conference on Harmonization (ICH 1996), an adverse event is "any untoward medical occurrence in a patient or clinical investigation subject administered a pharmaceutical product and which does not necessarily have a causal relationship with this treatment." Serious adverse events include those that require or prolong hospitalization, cause congenital anomalies, birth defects, or persistent or significant disability, are life threatening, or result in death. Health Canada and FDA requires all suspected serious or unexpected adverse events to be reported to the Canada Vigilance Program through MedEffect Canada or MedWatch FDA. These reports are then studied for pharmacovigilance activities including determining safety signals for products, which can highlight potential associations between an adverse event and a health product (Health Canada 2018).

Adverse events are generally underreported, especially when they involve NHPs. Previous studies show that $91 \%-99 \%$ of adverse events are not reported (Fletcher 1991; Martin et al. 1998; Hazell and Shakir 2006). One of the main reasons behind underreporting of these events is that patients do not disclose the use of NHPs to their health care practitioners (Hussain 2011; Vohra et al. 2012). Other reasons include difficulty in identifying adverse events related to NHPs, how to report NHP-specific reactions, finding the reaction not severe enough to report, and occupational time constraints ( J. Barnes et al. 1998; Vickers et al. 2006; Ide et al. 2016; Hohl et al. 2018). Various surveys about the use of CIM and NHPs show $56 \%-72 \%$ of patients did not disclose the use of NHPs to their health care practitioners (Eisenberg et al. 2001; Kennedy 2005; Jean and Cyr 2007; Jou and Johnson 2016). For pediatric patients, only $30 \%-65 \%$ of families discuss NHP use with health care practitioners (Chan 2002; Cala et al. 2003; Adams et al. 2013; Galicia-Connolly et al. 2014). Although some health care practitioners believe that CIM can offer benefits, many are concerned about potential side effects, the delay in use of approved treatments, patients taking CIM as an alternative to conventional medicine, and interferences with doctor-patient communication (Kemper and O'Connor 2004; Wardle and Adams 2014). Given the popular use of NHPs specifically herbal remedies, alongside pharmaceuticals in pediatric ADHD and the lack of communication about NHPs between practitioners and families, the safety of concomitant use warrants more investigation, especially adverse events potentially caused by NHP-drug interactions.

Accordingly, the objectives of this study were to identify adverse event reports (AERs) involving commonly used herbal remedies and ADHD prescription medicines, to evaluate the quality of collected AERs, and to assess whether NHP-drug interactions can be causally linked to reported adverse events.

\section{Methods}

We searched the literature and identified 22 herbal remedies (Table 1) used by pediatric patients with ADHD or other neurological disorders (Chan et al. 2000, 2003; Chan 2002; Cala et al. 2003; Pellow et al. 2011; Galicia-Connolly et al. 2014). AERs involving the 22 herbal remedies were searched and identified on the FDAble LLC database. FDAble contains data from FDAs drug Adverse Event Reporting System (FAERS). We chose to search on FDAble as it contains reports submitted in the United States, and internationally, and provides the most amount of open access information at the case level compared with other adverse event reporting systems (Fouretier et al. 2016). Identified reports meeting the inclusion criteria were obtained from the FDA Freedom of Information. An expert committee of adjudicators assessed these reports for quality and probability of NHP-drug interaction using various completeness and causality scales. The researchers did not have access to patient or reporter identifiers such as name or contact information. 
Table 1. Search Terms Including Common Name and Genus Used for the Systematic Search on FDAble

Database for Herbal Remedies Used by Pediatric Patients (4-18 Years)

Herbal remedy common name/alternative spelling (if applicable)

Genus name

Bacopa

Chamomile/camomile

Echinacea

Eleuthero

Evening primrose oil

Garlic

Ginger

Ginkgo/ginkgo

Ginseng

Goldenseal/golden seal

Green tea

Kava kava

Lemon balm

Linden

Passion flower

Peppermint

Pycnogenol

Rhodiola

Rosemary

Skullcap/skull cap

St. John's wort

Valerian

\section{Identification of AERs}

We systematically searched the FDAble LLC database using the advanced search option (see Fig. 1 for systematic search flowchart). We searched for 22 herbal remedies used by patients (4-18 years old) from 1997 to 2015 . Herbal remedies were searched using their common name, genus, and alternative names/spelling (if applicable) (Table 1).

For each AERs identified for a given herbal remedy, a subsearch was performed for reports that also included ADHD drugs (search terms included generic and brand names for different formulations): methylphenidate (Biphentin ${ }^{\circledR}$, Concerta $^{\circledR}$, Daytrana ${ }^{\circledR}$, Focalin $^{\circledR}$, Metadate $^{\circledR}$, Methyllin $^{\circledR}$, Quillivant ${ }^{\circledR}$, and Ritalin $\left.{ }^{\circledR}\right)$, amphetamine $\left(\right.$ Adderall $^{\circledR}$, Dexedrine ${ }^{\circledR}$, Dextrostat ${ }^{\circledR}$, Procentra ${ }^{\circledR}$, Vyvanse $^{(}$, and Zenzedi ${ }^{\circledR}$ ), guanfacine (Intuniv ${ }^{\circledR}$ ), and atomoxetine $\left(\right.$ Strattera $\left.^{\circledR}\right)$. Total number of reports for each herbal remedy and number of reports with ADHD drugs were recorded. The case number, primary suspect drug(s), adverse reactions, patient outcomes, manufacturer sending report, age (years), sex, and event date were recorded and submitted to the FDA Freedom of Information to obtain full copies of the report.

\section{AER data extraction}

We used the Gardiner Extraction Tool (Gardiner et al. 2013) to mine, collect, and organize data from each case report. The extraction form contained a total of 33 fields for patient information, adverse event, health information, laboratory tests, and herbal product information.

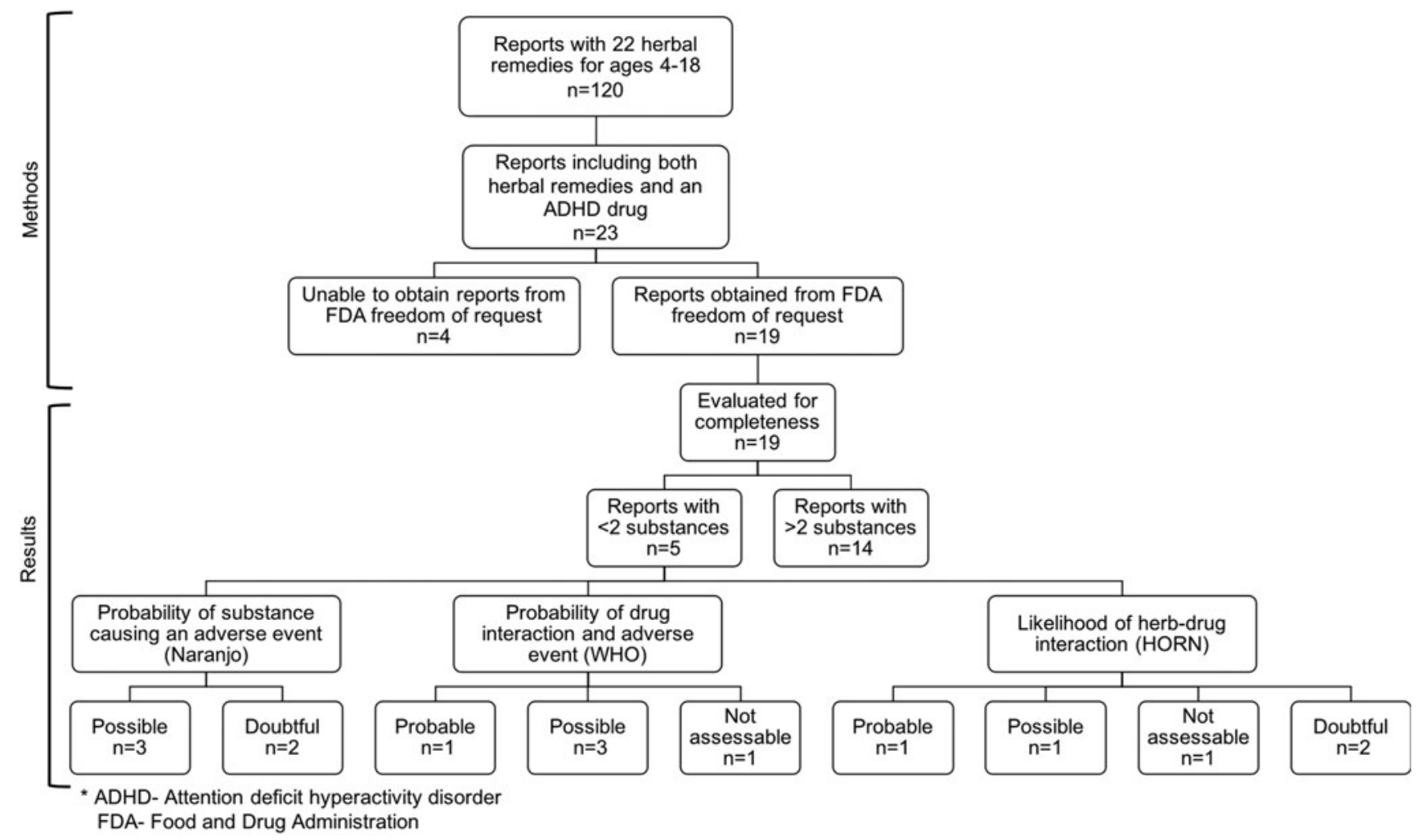

FIG. 1. Flowchart of systematic search results from 1997 to 2015 from FDAble of adverse event reports found for commonly used herbal remedies by children (4-18 years). 


\section{Completeness scales}

Three completeness scales were used to assess the quality of the AERs. The Berman and Ernst Scale (Fugh-Berman and Ernst 2001) is a 10-point scoring system used to confirm whether reports contain adequate information to be further assessed for NHP-drug interaction causality. Reports with scores between 0 and 3 are unevaluable, 4 and 7 have some evidence upon which to evaluate an interaction, and 8 and 10 represent well-documented reports.

The Gardiner Adherence Scale was developed and adapted for herbal remedies by Gardiner et al. (2013) and adhered with the Guidelines for Submitting Adverse Event Reports for Publication based on the International Society of Epidemiology criteria (Kelly et al. 2007). The scale shows the basic level of information that is necessary in pediatric case reports of adverse events involving an herbal remedy use. The total adherence score was out of 17.

Finally, we used the Gardiner Extraction Tool as a secondary measure of completeness to provide specific details about missing information relevant to NHPs. Each field present was given a score of 1 , and absent fields were assigned a score of 0 (Gardiner et al. 2013). A total score out of 33 was calculated for each report, and percent completeness was calculated with each scale.

\section{Causality assessment and assessment tools}

Previously validated Naranjo Adverse Drug Reaction Probability Scale (Naranjo et al. 1981), HORN Drug Interaction Probability Scale (HORN DIPS) (Horn et al. 2007), and World Health Organization Uppsala Monitoring Centre (WHO-UMC) Scale Causality Categories (World Health Organization 2015) were modified specifically for NHPs (Necyk 2013) and used to determine the probability of NHP-drug interaction among the collected AERs. AERs involving one herbal remedy and one drug were used for evaluation. First, each report was assessed by four adjudicators (psychiatrist, Health Canada pharmacologist, pharmacist, and a PhD student). Packages containing the AERs, extraction form, and completeness scores were sent to adjudicators along with modified Naranjo, HORN, and WHO drug interaction scales. Naranjo tool was to be filled out if the adverse reaction was thought to be due to a single substance, and HORN and WHO scales were to be completed for potential NHP-drug interactions.

Naranjo Adverse Drug Reaction Probability Scale. A tool that estimates the probability of a drug causing an adverse event using the known categories of definite, probable, possible, and doubtful adverse drug reactions (Naranjo et al. 1981).

HORN Drug Interaction Probability Scale. The HORN DIPS uses a series of questions to help to determine a probability score for a drug-drug interaction (Horn et al. 2007).

World Health Organization Uppsala Monitoring Centre Scale. WHO-UMC is a system created by the Programme for International Drug Monitoring and assesses case reports for drug interactions and adverse reactions using causality category terms (World Health Organization 2015).

The independent assessments were then discussed among the adjudicators to determine a final assessment.

\section{Results}

\section{Identification of AERs}

The systematic search of the FDAble database identified 120 AERs including the 22 targeted herbal remedies. Observing the outcomes of the reports indicated that $38.3 \%$ of the adverse events resulted in hospitalization, $5.8 \%$ in deaths, $3.3 \%$ were life threatening, $5 \%$ resulted in disability, $31.7 \%$ were medically significant or other, and $15.8 \%$ of the reports did not report an outcome.

Twenty-three (19.2\%) of the 120 AERs involved an ADHD prescription drug. In these 23 reports, 8 herbal remedies were identified: Echinacea (6), evening primrose oil (3), garlic (2), Ginkgo biloba (3), ginseng (4), green tea (1), St. John's wort (2), and valerian (2) (Fig. 2).

From the 23 reports involving ADHD prescription drugs, we identified 5 AERs that reported the use of only 2 products $(1$ herbal

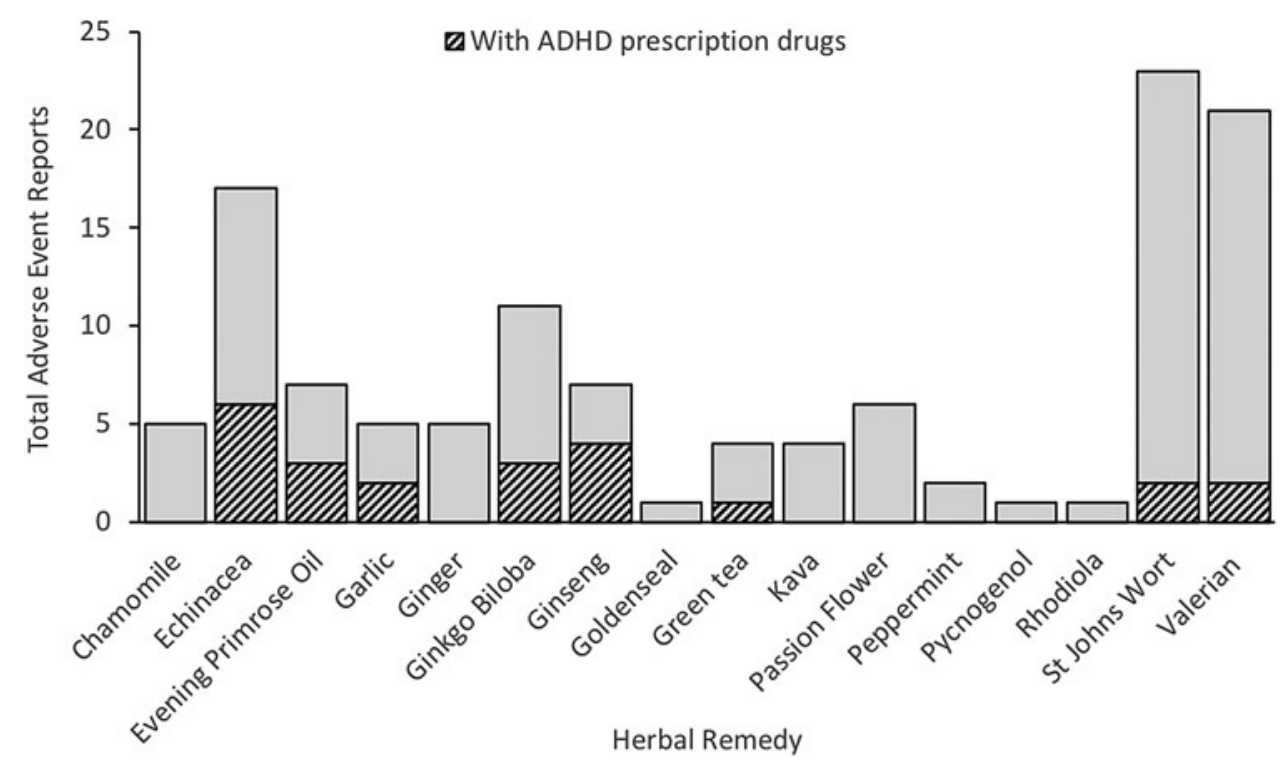

FIG. 2. Total number of adverse event reports for commonly used herbal remedies by children, and adverse events with prescription drugs used for attention-deficit/hyperactivity disorder for children aged 4-18 years from 1997 to 2015 using FDAble advance search. 
remedy with 1 ADHD drug). These reports were subsequently evaluated for NHP-drug interaction potential. We did not evaluate reports with more than two products being used concurrently as it can be difficult to determine causality when a patient has consumed multiple medications due to the possibility of multiple interactions (both NHP-drug and drug-drug interactions). Among the other 18 reports (including the 4 reports we were unable to obtain from the FDA freedom of request) involving the use of an ADHD drug, and 2 or more NHPs, most patients were taking between 4 and 10 different products.

\section{Assessment of completeness}

Assessment of completeness was conducted on the reports obtained from the FDA freedom of request $(n=19)$ (Fig. 1).

For the Berman and Ernst Scale, the mean completeness score was 4.6 out of 10 , meaning that the reports provide some evidence for an interaction, but there may be other causes of the event. Six reports had a score between 0 and 3,11 reports had a score between 4 and 7 , and 2 reports had a score of 8 . Information on patient history and concurrent diseases, conditions, and medications was provided in most cases. The following categories were poorly described in the reports: description of interactors, obvious alternative explanations excluded, chronology, time sequence to drug administration and adverse event, challenge, and rechallenge information.

For the assessment of completeness using the Gardiner Adherence Scale (Gardiner et al. 2013), the average adherence score was 6.2 out of 17 (range: 2-12). In general, the following categories were poorly reported: physical examination, patient disposition, herbal product information, dosage, duration of herbal remedy use before adverse event, concomitant therapies, and discussion. The patient demographics, health status, medical history, and description of adverse event were almost always provided.

We also used the Gardiner Extraction Tool, which was developed for assessing the completeness of AERs involving NHP/ supplements. A total score out of 33 was assigned to each of the 19 AERs obtained from the FDA freedom of request, yielding an average score of 10.05 (30.4\% completeness, range: 4-16). As illustrated in the heat map in Figure 3, NHPs product information and laboratory test results were rarely reported. Although the description of the adverse event was always reported, patient and health information was generally lacking in the reports. This information is necessary to better evaluate the adverse event for causality.

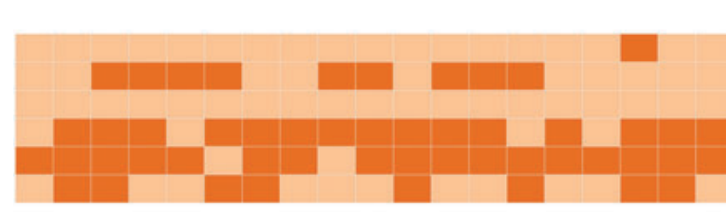

Patient Information

Age

Weight

Gender

Race/Ethnicity

Country of origin

Country $\mathrm{AE}^{\star}$ occurred

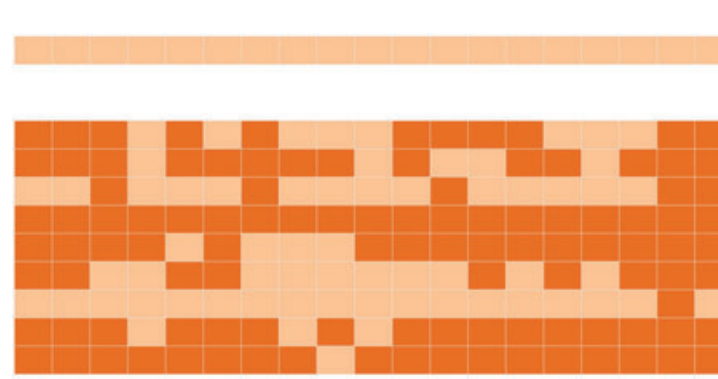

Adverse Event

Description

Health Information

Disease, condition or symptom treated

Prior use of product

Medical history relevent to $\mathrm{AE}^{*}$

Toxins exposure

Physical exam findings

Patient disposition at time of report

Concomitant OTC ${ }^{\star}$, prescription, alcohol or other therapies

Assessment of concominant therpies

Product recommendation

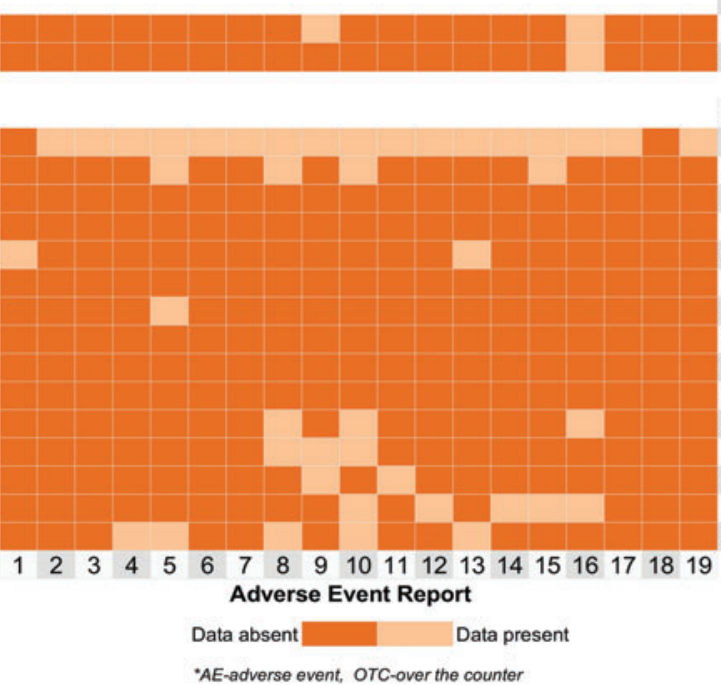

Lab tests

Blood profile

Urine Profile

Product Information

Name of Natural Health Product

Latin binomial name

Lab testing of Natural Health Product

Metal level testing

Other metal level testing

Product ingredients

Plant part(s) listed

Type of preparation

Name of product manufacture

Country of production

Approximate dose taken

Duration of exposure

Duration of exposure before $\mathrm{AE}^{*}$

Route of administration

Challenge, dechallenge, rechallenge

-AE-adverse event, OTC-over the counter

FIG. 3. Heat map of information available in 19 pediatric adverse event reports involving commonly used herbal remedies by children and prescription drugs used for attention-deficit/hyperactivity disorder. The categories on the $y$-axis were utilized from the Gardiner Extraction Tool (Gardiner et al. 2013). Color images are available online. 


\section{AERs involving an $A D H D$ drug and an herbal remedy}

A summary of the five pediatric cases involving only an ADHD medication and an herbal remedy is presented below, based on all the information available in the AERs obtained from the FDA. Refer to Table 2 for associated case number, case key features, completeness, and adjudication.

Case I: An 8-year-old male with a history of ADHD, astigmatism, conduct disorder, learning disorder, and asthma was taking Strattera $25 \mathrm{mg}$ for ADHD from October 2008 to September 2009. He was taking G. biloba $85 \mathrm{mg}$ daily from May 2001 to November 2010. After starting Strattera, patient experienced headache and eye pain that resulted in hospitalization. Ophthalmologic examination raised suspicion of glaucoma. The reporting child psychiatrist stated that the event was related to Strattera.

Case II: A 7-year-old female was treated with Ritalin $10 \mathrm{mg} /$ day orally for ADHD starting October 2001. Patient was also receiving Efalex evening primrose oil (supplementing fatty acids) since 2001. On March 7, 2002, she developed a tic involving both her arms, and it became more complex involving hands, fingers, wrists, neck, head, and hips. Ritalin was discontinued on March 7, 2002. After discontinuation, there was improvement in the movement of head, arm, neck, and legs, but the movements were still present. There was no family history of tics or of a movement disorder. Before the tics, the patient experienced nightmares for 1 week. She also had a skin rash and dry skin around her mouth. The case was considered medically significant.

Case III: An 11-year-old male was taking OROS (osmotic release o system) methylphenidate $36 \mathrm{mg}$ daily orally for ADHD for a few years. The patient was also taking evening primrose oil for an unknown indication and duration. Patient was adopted and may have been exposed to drugs prenatally. He had a history of moderate-to-severe developmental delay and slow learning. On December 30, 2002, he ran out of OROS methylphenidate and had to be taken to the emergency with severe torticollis, rolling arm movements, lip chewing, slight pharyngitis. On January 2, 2003, he presented to his pediatrician with the same symptoms and slurred speech, and not eating or drinking and was admitted to the hospital. The patient was also taking evening primrose oil for unknown indication and duration. Torticollis improved with intravenous cetirizine hydrochloride. Patient was further diagnosed with pharyngeal abscess.

Case IV: A 17-year-old female with history of ADHD and depression was treated with OROS methylphenidate for about a year. Concurrent medication included St. John's wort. Patient experienced psychotic symptoms on an unknown day. Patient was seeing and hearing things in the night, which were not there, and was disturbed. The outcome was deemed medically significant.

Case V: A 15-year-old male started Ritalin $20 \mathrm{mg}$ orally/day in 1998 for ADHD and tolerated it well. He had a period of sadness and took St. John's wort (five drops) orally daily to treat his depression starting June 1, 2001. A few hours later, he presented agitation, unexplained weeping, aggressiveness alternating with depression, and difficulty in concentrating. On June 6, 2001, St. John's wort was discontinued and these symptoms abated. Three weeks later, St. John's wort was reinitiated and the same symptoms occurred. St. John's wort was discontinued again and the symptoms abated again. The reaction was considered medically significant.

Cases I and II were adjudicated as doubtful for HORN DIPS and possible for both WHO and Naranjo scales. Case III did not have adequate information on the timeline and dosage of evening primrose oil to determine an interaction with both HORN DIPS and WHO scale. For Naranjo scale, it was decided that although an interaction with methylphenidate (Concerta) could not be completely ruled out, again due to lack of information the adjudicators decided on a doubtful possibility of a reaction with methylphenidate.

Case IV was deliberated to have a possible likelihood of an interaction between St. John's wort and Concerta for HORN DIPS and WHO scale. Although St. John's wort and Concerta alone could be the cause of an acute psychotic reaction due to an increase in dopaminergic transmission (Naranjo-possible likelihood), St. John's wort is a known inhibitor of P-glycoprotein and could lead to an increasing concentration of methylphenidate in the brain (Zhu et al. 2006, 2008). However, the role of P-glycoprotein in the transport of D-methylphenidate is likely to be minor (Zhu et al. 2008).

Case V was adjudicated as probable for HORN DIPS and Naranjo and probable/likely for WHO scale. Although we are unaware of previous reports of this interaction, excessive weeping, agitation, and aggressiveness can appear during Ritalin treatment (Novartis Pharmaceuticals Canada, Inc. 2017). Concomitant use of St. John's wort could exacerbate this as they share similar modes of action, and St. John's wort is an inhibitor of P-glycoprotein, which could result in higher plasma levels of Ritalin. This case has a probable likelihood of an interaction as the adverse event appeared a few hours after administration of St. John's wort and the reaction stopped when St. John's wort was discontinued then reappeared upon rechallenge with St. John's wort.

\section{Discussion}

Our systematic search found 120 AERs involving commonly used herbal remedies by pediatric patients. Of these, $23(19.2 \%)$ AERs involved an ADHD medication. With the widespread use of NHPs, including herbal remedies among pediatric patients across different clinical populations, the high relative prevalence of AERs involving ADHD drugs in the 120 reports we found may reflect a high prevalence of ADHD diagnoses in the United States. However, it may also suggest an elevated risk of interaction between phytochemicals and ADHD medications. Since AERs often go unreported, particularly those related to CIM, the collected AERs likely reflect a fraction of such events but nonetheless offer an important tool for monitoring and investigating potential NHP-drug interactions.

Of the 23 identified AERs involving both an herbal remedy and an ADHD drug, most involved multiple ( $>3$ ) substances with inadequate detail to assess multiple potential interactions. Idiosyncratic reactions (NHP-NHP reactions) may play a role in AERs involving multiple products.

Following data extraction and evaluation of completeness, five AERs that involved only one herbal remedy and one ADHD drug were evaluated for causality. Based on consensus adjudication using the HORN scale, the likelihood of an NHP-drug interaction was assessed to be probable in one case and to be possible in another. Both these reports (Cases IV and V) involved a methylphenidate formulation (Concerta and Ritalin) and St. John's wort.

St. John's wort is known to interact with various drugs through several mechanisms. In these cases, a possible mechanism could be that St. John's wort inhibits P-glycoprotein affecting the concentration of methylphenidate in the blood and the brain (Dürr et al. 2000; Perloff et al. 2001; Zhu et al. 2006). Additionally, St. John's wort is known to inhibit numerous drug-metabolizing enzymes including the cytochrome P450 (CYP) family (Markowitz et al. 2000, 2003; Obach 2000; Komoroski et al. 2004). Amphetamine 


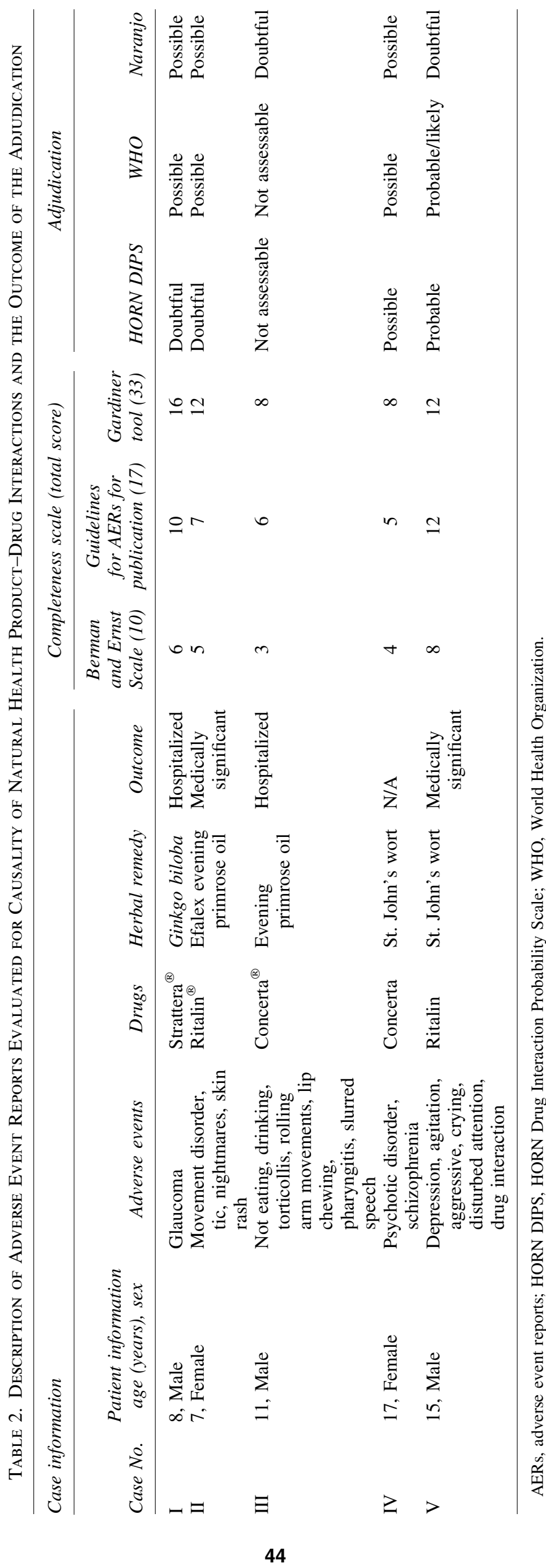


and atomoxetine are metabolized by hepatic CYP enzymes, but methylphenidate is converted to inactive ritalinic acid by carboxylesterase 1 (CES1). Liver CES1 is responsible for the hydrolysis of both D- and L-isomers of methylphenidate (the two components of Ritalin or Concerta) and for the resulting first-pass metabolism of the drug. Many natural inhibitors of CES1 and a few inducers are found in herbal products (Xu et al. 2018), but the effects of St. John's wort on methylphenidate metabolism and CES1 have yet to be studied.

It is vital to highlight the low quality of AERs examined in this study. Our investigation revealed an overall mean completeness score of 10.05 out of 33 using the Gardiner Extraction Tool and 6.2 out of 17 on the Gardiner Adherence Scale. As well, an average score of 4.6 out of 10 on the Berman and Ernst completeness scale suggests that reports provided some evidence for an interaction, but that other causes may underlie or have contributed to the adverse event. This degree of (in)completeness both complicated adjudication of potential herb-drug interactions and highlights poor reporting guidance with regard to NHPs. The most consistently missing information was details on the herbal remedies (such as Latin binomial name, product ingredients, plant parts, type of preparation, name of manufacturer, dose, country of production, duration of exposure, route of administration) and other concomitant therapeutics, which are vital to determine an interaction. This makes it difficult to assess the likelihood of an NHP-drug interaction and decreases the reliability of the AERs.

When documented thoroughly, AERs can be an important tool to determine the safety of a product post-market. Well-documented AERs can inform health care practitioners about the possibility of the risk associated with a product alone, or in combination with others, and they can inform regulatory agencies to re-evaluate a product safety signal to determine if it will remain on the market. Overall, they can aid to prevent the reoccurrence of the adverse event in patients (Kelly et al. 2007) and to identify combinations of therapeutics that may present risk and require testing in vitro and in vivo to confirm NHP-drug interaction causality. Importantly, despite missing information, our study identified potential interactions that warrant further attention and investigation.

Given the popularity and out-of-pocket costs associated with CIM use, it is important for the public to have convenient access to evidence-based information for informed decision-making.

Moreover, communication about NHPs between health care practitioners and families is important, and clinics and hospitals should provide regular educational seminars to health care providers about safety, especially in the case of polypharmacy. Improved communication with health care practitioners could also reduce instances of delays in diagnosis and in seeking approved treatment from CIM use and can improve adherence with conventional treatment. More awareness about pharmacovigilance is also important. One way to increase pharmacovigilance of NHPs is consumer education on awareness and reporting of adverse events, which in turn can increase the quality of consumer reports (World Health Organization 2005b, 2015; Kelly et al. 2007).

There were some limitations to this study. The AERs assessed were all in English language; therefore, we were not able to capture if non-English AERs exhibit similar trends for quality and adverse events. The quality of AERs in general was low, and readers should exercise caution when interpreting the results. Other NHPs commonly used by pediatric ADHD patients that were not included in this study, but may pose similar risk of interaction, such as melatonin, caffeine, blue green algae, and unsaturated fatty acid supplements, warrant investigation. The identified AERs may reflect off-label use, or the lack of evidence of safe use of NHPs in children, rather NHP-drug interactions. However, this caveat is difficult to gauge for children with ADHD because of the lack of clinical data on the use, efficacy, or safety in this population. Specifically, due to the prevalence of comorbid psychiatric disorders, it is not clear whether children taking NHPs do so to alleviate ADHD symptoms, symptoms from other conditions, or for maintaining general health.

\section{Conclusion}

We identified 23 AERs involving both an herbal remedy and an ADHD drug in a pediatric population. Overall, the quality of these reports was low. Eighteen of these reports involved multiple $(>3)$ substances with inadequate detail to assess multiple potential interactions. The five AERs examined for NHP-drug interaction causality adjudication using the HORN DIPS showed likelihood of an NHP-drug interaction to be probable in one case and to be possible in another. Both these reports (Cases IV and V) involved a methylphenidate formulation (Concerta and Ritalin) and St. John's wort.

\section{Clinical Significance}

Health care practitioners, particularly those treating pediatric ADHD patients, need to be aware of risks of NHP interactions and need to maintain a dialog about the use of these products. Given the demands and priorities set upon emergency room staff and other health care practitioners dealing with adverse events, establishing extensive NHP-specific protocols is impractical. However, since our results highlight the difficulty in assessing AERs involving herbal remedies due to lack of information, regulating bodies such as the FDA could implement simple tools to improve report quality with limited impact on frontline resources, for example, a checklist of details required to assess AERs involving NHPs: a product name (brand/ingredients and manufacturer), dose, route, dates of duration of use, and indication for use. Additional information desired that could be helpful to assess causality of the reports includes: regulatory identification number (if available: such as in Canada, natural product number, drug identification number, or homeopathy drug identification number), Latin binomial name of ingredients, plant part, type of preparation, and challenge/dechallenge/ rechallenge information.

\section{Acknowledgments}

The authors thank Emmerson Harkin, Étienne Rhéaume, and Saipranay Guntaka for their help in searching the FDAble.com database and data extraction.

\section{Disclosures}

The authors have no conflicts of interest to disclose.

\section{References}

Adams D, Dagenais S, Clifford T, Baydala L, King WJ, Hervas-Malo M, Moher D, Vohra S: Complementary and alternative medicine use by pediatric specialty outpatients. Pediatrics 131:225-232, 2013.

Ball SD, Kertesz D, Moyer-Mileur LJ: Dietary supplement use is prevalent among children with a chronic illness. J Am Diet Assoc 105:78-84, 2005. 
Barnes J, Mills SY, Abbot NC, Willoughby M, Ernst E: Different standards for reporting ADRs to herbal remedies and conventional OTC medicines: Face-to-face interviews with 515 users of herbal remedies. Br J Clin Pharmacol 45:496-500, 1998.

Barnes PM, Bloom B, Nahin RL: Complementary and alternative medicine use among adults and children: United States, 2007. Natl Health Stat Report 10:1-23, 2008.

Benzie IFF, Wachtel-Galor S: Herbal Medicine: Biomolecular and Clinical Aspects. Boca Raton, FL: CRC Press, 2011.

Birdee GS, Phillips RS, Davis RB, Gardiner P: Factors associated with pediatric use of complementary and alternative medicine. Pediatrics 125:249, 2010.

Cala S, Crismon ML, Baumgartner J: A survey of herbal Use in children with attention-deficit-Hyperactivity disorder or depression. Pharmacother J Hum Pharmacol Drug Ther 23:222-230, 2003.

Chan E: The role of complementary and alternative medicine in attention-deficit hyperactivity disorder. J Dev Behav Pediatr 23: S37-S45, 2002.

Chan E, Gardiner P, Kemper KJ: "At least it's natural ..." herbs and dietary supplements in ADHD. Contemp Pediatr 17:116, 2000.

Chan E, Rappaport LA, Kemper KJ: Complementary and alternative therapies in childhood attention and hyperactivity problems. J Dev Behav Pediatr 24:4-8, 2003.

Cheng C-W, Fan W, Ko S-G, Song L, Bian Z-X: Evidence-based management of herb-drug interaction in cancer chemotherapy. Explor J Sci Heal 6:324-329, 2010.

Dürr D, Stieger B, Kullak-Ublick GA, Rentsch KM, Steinert HC, Meier PJ, Fattinger K: St John's Wort induces intestinal P-glycoprotein/MDR1 and intestinal and hepatic CYP3A4. Clin Pharmacol Ther 68:598-604, 2000.

Eisenberg DM, Kessler RC, Van Rompay MI, Kaptchuk TJ, Wilkey SA, Appel S, Davis RB: Perceptions about complementary therapies relative to conventional therapies among adults who use both: Results from a national survey. Ann Intern Med 135:344-351, 2001

Esmail N: Complementary and alternative medicine: use and public attitudes 1997, 2006, and 2016. 2017. www.fraserinstitute.org/sites/ default/files/complementary-and-alternative-medicine-2017.pdf (accessed September 20, 2019).

Fletcher AP: Spontaneous adverse drug reaction reporting vs event monitoring: A comparison. J R Soc Med 84:341-344, 1991.

Fouretier A, Malriq A, Bertram D: Open Access Pharmacovigilance databases: Analysis of 11 databases. Pharmaceut Med 30:221-231, 2016.

Fugh-Berman A, Ernst E: Herb-drug interactions: Review and assessment of report reliability. Br J Clin Pharmacol 52:587-595, 2001

Galicia-Connolly E, Adams D, Bateman J, Dagenais S, Clifford T, Baydala L, King WJ, Vohra S: CAM use in pediatric neurology: An exploration of concurrent use with conventional medicine. PLoS One 9:e94078, 2014.

Gardiner P, Adams D, Filippelli AC, Nasser H, Saper R, White L, Vohra S: A systematic review of the reporting of adverse events associated with medical herb use among children. Glob Adv Heal Med 2:46-55, 2013.

Hazell L, Shakir SAW: Under-reporting of adverse drug reactions. Drug Saf 29:385-396, 2006.

Hazell PL, Walton JM, McDowell MJ: Management of children prescribed psychostimulant medication for attention deficit hyperactivity disorder in the Hunter region of NSW. Med J Aust 165: 477-480, 1996.

Health Canada: About natural health products. 2015. www.canada .ca/en/health-canada/services/drugs-health-products/natural-nonprescription.html (accessed February 21, 2019).
Health Canada: Reporting adverse reactions to marketed health products-Guidance document for industry. 2018. www.canada.ca/ en/health-canada/services/drugs-health-products/reports-publications/ medeffect-canada/reporting-adverse-reactions-marketed-healthproducts-guidance-industry.html (accessed March 16, 2019).

Hohl CM, Small SS, Peddie D, Badke K, Bailey C, Balka E: Why clinicians don't report adverse drug events: Qualitative study. JMIR Public Heal Surveill 4:1-11, 2018.

Horn JR, Hansten PD, Chan L-N: Proposal for a new tool to evaluate drug interaction cases. Ann Pharmacother 41:674-680, 2007.

Huang A, Seshadri K, Matthews TA, Ostfeld BM: Parental perspectives on use, benefits, and physician knowledge of complementary and alternative medicine in children with autistic disorder and attention-deficit/hyperactivity disorder. J Altern Complement Med 19:746-750, 2013.

Hussain S: Patient counseling about herbal-drug interactions. Afr J Tradit Complement Altern Med 8(5 Suppl):152-163, 2011.

ICH Expert Working Group: Guidline for good clinical practice E6(R1). International Conference on Harmonization of Technical Requirements for Registration of Pharmaceuticals for Human Use. IHC, Geneva, Switzerland, 1996.

Ide K, Yamada H, Kawasaki Y, Noguchi M, Kitagawa M, Chiba T, Kagawa Y, Umegaki K: Reporting of adverse events related to dietary supplements to a public health center by medical staff: A survey of clinics and pharmacies. Ther Clin Risk Manag 12:1403, 2016.

Ipsos: Natural health product tracking survey-2010 Final report. Health Canada, 2011. www.int4life.ca/uploads/5/1/5/1/5151557/ 2010_report.pdf (accessed February 19, 2019).

Jean D, Cyr C: Use of complementary and alternative medicine in a general pediatric clinic. Pediatrics 120:e138-e141, 2007.

Jou J, Johnson PJ: Nondisclosure of complementary and alternative medicine use to primary care physicians: Findings from the 2012 National Health Interview Survey. JAMA Intern Med 176:545-546, 2016.

Kelly WN, Arellano FM, Barnes J, Bergman U, Edwards IR, Fernandez AM, Freedman SB, Goldsmith DI, Huang K, Jones JK, McLeay R: Guidelines for submitting adverse event reports for publication. Pharmacoepidemiol Drug Saf 16:581-587, 2007.

Kemper KJ, Gardiner P, Birdee GS: Use of complementary and alternative medical therapies among youth with mental health concerns. Acad Pediatr 13:540-545, 2013.

Kemper KJ, O'Connor KG: Pediatricians' recommendations for complementary and alternative medical (CAM) therapies. Ambul Pediatr 4:482-487, 2004.

Kennedy J: Herb and supplement use in the US adult population. Clin Ther 27:1847-1858, 2005.

Komoroski BJ, Zhang S, Cai H, Hutzler JM, Frye R, Tracy TS, Strom SC, Lehmann T, Ang CY, Cui YY, Venkataramanan R: Induction and inhibition of cytochromes P450 by the St. John's wort constituent hyperforin in human hepatocyte cultures. Drug Metab Dispos 32:512-518, 2004.

Loman DG: The use of complementary and alternative health care practices among children. J Pediatr Heal Care 17:58-63, 2003.

Markowitz JS, DeVane CL, Boulton DW, Carson SW, Nahas Z, Risch SC: Effect of St. John's wort (Hypericum perforatum) on cytochrome P-450 2D6 and 3A4 activity in healthy volunteers. Life Sci 66:PL133-PL139, 2000.

Markowitz JS, Donovan JL, DeVane CL, Taylor RM, Ruan Y, Wang JS, Chavin KD: Effect of St John's wort on drug metabolism by induction of cytochrome P450 3A4 enzyme. JAMA 290:15001504, 2003.

Martin RM, Kapoor KV, Wilton LV, Mann RD: Underreporting of suspected adverse drug reactions to newly marketed ("black tri- 
angle") drugs in general practice: Observational study. BMJ 317: 119-120, 1998.

Naranjo CA, Busto U, Sellers EM, Sandor P, Ruiz I, Roberts EA, Janecek E, Domecq C, Greenblatt DJ: A method for estimating the probability of adverse drug reactions. Clin Pharmacol Ther 30:239245, 1981.

National Center for Complementary and Integrative Health: Americans spent $\$ 30.2$ billion out-of-pocket on complementary health approaches. 2016. https://nccih.nih.gov/news/press/cost-spending06222016 (accessed September 23, 2019).

National Center for Complementary and Integrative Health: Complementary, alternative, or integrative health: What's in a name?. 2018. https://nccih.nih.gov/health/integrative-health (accessed March 16, 2019).

Necyk C: The Detection and Causality Assessment of Adverse Events Related to Natural Health Product Use in Community Pharmacies through the Implementation of Active Surveillance. Master of Science, Thesis. Edmonton, Department of Medicine, University of Alberta, 2013.

Neuhouser ML, Patterson RE, Schwartz SM, Hedderson MM, Bowen DJ, Standish LJ: Use of alternative medicine by children with cancer in Washington state. Prev Med 33:347-354, 2001.

Noras MR, Yousefi M, Kiani MA: Complementary and alternative medicine (CAM) use in pediatric disease: A short review. Int $\mathrm{J}$ Pediatr 1:45-49, 2013.

Novartis Pharmaceuticals Canada, Inc.: Product Monograph RITALIN $^{\circledR}$ (methylphenidate hydrochloride). Dorval, Canada: Novartis Pharmaceuticals Canada, 2017.

Obach RS: Inhibition of human cytochrome P450 enzymes by constituents of St. John's Wort, an herbal preparation used in the treatment of depression. J Pharmacol Exp Ther 294:88-95, 2000.

Ottolini MC, Hamburger EK, Loprieato JO, Coleman RH, Sachs HC, Madden R, Brasseux C: Complementary and alternative medicine use among children in the Washington, DC area. Ambul Pediatr 1: 122-125, 2001.

Pellow J, Solomon EM, Barnard CN: Complementary and alternative medical therapies for children with attention-deficit/hyperactivity disorder (ADHD). Altern Med Rev 16:323, 2011.

Perloff MD, Von Moltke LL, Störmer E, Shader RI, Greenblatt DJ: Saint John's wort: An in vitro analysis of P-glycoprotein induction due to extended exposure. Br J Pharmacol 134:1601-1608, 2001.

Post-White J, Fitzgerald M, Hageness S, Sencer SF: Complementary and alternative medicine use in children with cancer and general and specialty pediatrics. J Pediatr Oncol Nurs 26:7-15, 2009.

Sinha D, Efron D: Complementary and alternative medicine use in children with attention deficit hyperactivity disorder. J Paediatr Child Health 41:23-26, 2005

Spigelblatt L, Laîné-Ammara G, Pless IB, Guyver A: The use of alternative medicine by children. Pediatrics 94:811-814, 1994.

Stubberfield TG, Wray JA, Parry TS: Utilization of alternative therapies in attention-deficit hyperactivity disorder. J Paediatr Child Health 35:450-453, 1999.
The Council for Responsible Nutrition: 2018 CRN consumer survey on dietary supplements. 2018. www.crnusa.org/CRNConsumerSurvey (accessed May 13, 2019).

U.S. Food and Drug Administration: Dietary supplements. 2018. www .fda.gov/food/dietarysupplements (accessed May 13, 2019).

Vickers KA, Jolly KB, Greenfield SM: Herbal medicine: Women's views, knowledge and interaction with doctors: A qualitative study. BMC Complement Altern Med 6:40, 2006.

Vohra S, Cvijovic K, Boon H, Foster BC, Jaeger W, LeGatt D, Cembrowski G, Murty M, Tsuyuki RT, Barnes J, Charrois TL: Study of natural health product adverse reactions (SONAR): Active surveillance of adverse events following concurrent natural health product and prescription drug use in community pharmacies. PLoS One 7:e45196, 2012.

Wang C, Preisser J, Chung Y, Li K: Complementary and alternative medicine use among children with mental health issues: Results from the National Health Interview Survey. BMC Complement Altern Med 18:241, 2018.

Wardle JJL, Adams J: Indirect and non-health risks associated with complementary and alternative medicine use: an integrative refiew. Eur J Integr Med 6:409-422, 2014.

World Health Organization: National Policy on Traditional Medicine and Regulation of Herbal Medicines: Report of a WHO Global Survey. Geneva, World Health Organization, 2005a.

World Health Organization: World Alliance for Patient Safety: WHO Draft Guidelines for Adverse Event Reporting and Learning Systems: From Information to Action. Geneva, World Health Organization, 2005b.

World Health Organization: WHO Guidelines on Safety Monitoring of Herbal Medicines in Pharmacovigilance Systems. Geneva, World Health Organization, 2015.

Xu J, Qiu JC, Ji X, Guo HL, Wang X, Zhang B, Wang T, Chen F: Potential pharmacokinetic herb-drug interactions: Have we overlooked the importance of human carboxylesterases 1 and 2? Curr Drug Metab 20:130-137, 2018.

Zhu HJ, Wang JS, DeVane CL, Williard RL, Donovan JL, Middaugh LD, Gibson BB, Patrick KS, Markowitz JS: The role of the polymorphic efflux transporter P-glycoprotein on the brain accumulation of d-methylphenidate and d-amphetamine. Drug Metab Dispos 34:1116-1121, 2006.

Zhu HJ, Wang JS, Donovan JL, Jiang Y, Gibson BB, DeVane CL, Markowitz JS: Interactions of attention-deficit/hyperactivity disorder therapeutic agents with the efflux transporter P-glycoprotein. Eur J Pharmacol 578:148-158, 2008.

Address correspondence to: Hajra Mazhar, BSc Department of Biology Faculty of Science University of Ottawa

30 Marie Curie, Room GNN 283 Ottawa, ON K1N 6 N5

Canada

E-mail: hmazh057@uottawa.ca 